\title{
Risk Factors for Infection after 46,113 Intramedullary Nail Operations in Low- and Middle-income Countries
}

\author{
Sven Young $\cdot$ Stein Atle Lie $\cdot$ Geir Hallan $\cdot$ \\ Lewis G. Zirkle $\cdot$ Lars B. Engesæter • \\ Leif I. Havelin
}

Published online: 2 October 2012

(c) The Author(s) 2012. This article is published with open access at Springerlink.com

\begin{abstract}
Background The fields of surgery and trauma care have largely been neglected in the global health discussion. As a result the idea that surgery is not safe or cost effective in resource-limited settings has gone unchallenged. The SIGN Online Surgical Database (SOSD) is now one of the largest databases on trauma surgery in low- and middle-income countries (LMIC). We wished to examine infection rates and risk factors for infection after IM nail operations in LMIC using this data.

Methods The SOSD contained 46,722 IM nail surgeries in 58 different LMIC; 46,113 IM nail operations were included for analysis.

Results The overall follow-up rate was $23.1 \%$. The overall infection rate was $1.0 \%, 0.7 \%$ for humerus, $0.8 \%$ for femur, and $1.5 \%$ for tibia fractures. If only nails with registered follow-up $(n=10,684)$ were included in analyses, infection rates were $2.9 \%$ for humerus, $3.2 \%$ for femur, and $6.9 \%$ for tibia fractures. Prophylactic antibiotics reduced the risk
\end{abstract}

S. Young $(\bowtie) \cdot$ G. Hallan · L. B. Engesæter · L. I. Havelin Department of Orthopaedic Surgery, Haukeland University Hospital, Bergen, Norway

e-mail: svenyoung@gmail.com

S. Young · S. A. Lie - L. B. Engesæter · L. I. Havelin Department of Surgical Sciences, University of Bergen, Bergen, Norway

S. Young

Department of Surgery, Kamuzu Central Hospital, Lilongwe, Malawi

S. A. Lie · G. Hallan - L. B. Engesæter · L. I. Havelin

Norwegian Arthroplasty Register, Bergen, Norway

L. G. Zirkle

SIGN Fracture Care International, Richland, WA, USA of infection by $29 \%$. Operations for non-union had a doubled risk of infection. Risk of infection was reduced with increasing income level of the country.

Conclusions The overall infection rates were low, and well within acceptable levels, suggesting that it is safe to do IM nailing in low-income countries. The fact that operations for non-union have twice the risk of infection compared to primary fracture surgery further supports the use of IM nailing as the primary treatment for femur fractures in LMIC.

\section{Introduction}

Approximately 5.8 million people die annually as the result of injuries, more people than die of HIV/AIDS, tuberculosis, and malaria combined [1, 2]. Over $90 \%$ of these fatal injuries occur in low- and middle-income countries (LMIC). For every death from injury, 3-10 more people survive injury with a permanent disability [3, 4]. In young people between the ages of 10 and 24 years as many as $97 \%$ of deaths occur in LMIC, over $40 \%$ of deaths are related to injuries, and road traffic injuries are the most common cause [5]. The global burden of injuries is growing rapidly, and almost entirely in LMIC. By 2030 the World Health Organization (WHO) expects traffic accidents to have risen from the ninth to the fifth leading cause of all deaths globally [6]. Despite these compelling facts, surgery is not mentioned at all in the Millennium Development Goals (MDGs: http://www.un.org/millenniumgoals/) [7, 8]. At present, however, we are seeing increasing awareness of surgery as an integral part of the global public health effort to reach the MDGs [8-12]. Injuries disproportionately affect the younger segment of the population in LMIC and have a serious impact on the whole families of the injured. In LMIC 
with no functioning social security systems, the injury of a young mother or father, often the breadwinner of the family, can be devastating to their economic situation and push them further into poverty [13].

In high-income countries intra-medullary (IM) nailing of femoral shaft fractures is an established gold standard. However, the cost of IM nails and the fear of postoperative infection has prohibited their use in most LMIC, where traction most often still is the only treatment offered for femoral fractures $[14,15]$. In orthopedic surgery, skills and training are useless without the equipment to do the job. This is recognized by SIGN Fracture Care International (SIGN) which has developed a US Food and Drug Administration (FDA) approved IM nail specifically designed for use in resource- poor settings without the use of an image intensifier [16]. SIGN has provided over 80,000 IM nails, and training in their use, to over 200 hospitals in LMIC free of charge since 1999 (numbers; personal communication from SIGN, February 2012) [17]. Although there is growing evidence that orthopedic trauma surgery is necessary, safe, and cost-effective also in LMIC [18-21], more research is needed to confirm these findings and to bring this knowledge into the mainstream global health discussion. As a part of the resupply service for the hospitals supported by SIGN, the SIGN online surgical database (SOSD) was started in 2003. There are now over 46,000 registered IM nail operations in this database, making it possibly the largest available database on orthopedic trauma care in LMIC. Despite a fairly limited follow-up rate (18.1\% in 2010), validation of the data in the SOSD has suggested that it is reliable and can be used for further research [21]. The aim of the present study was to use the data in the SOSD to investigate whether the follow-up and infection rates are changing, and to identify risk factors for infection after IM nail operations in LMIC.

\section{Methods}

SIGN provided us with an anonymous export of all surgeries registered in the SOSD from the start of the registry in 2003 up to November 29, 2011. Ethical approval for this study was given by the Norwegian regional research ethics committee $(20.09 .10,2010 / 2040)$. The SOSD at the time of export contained data on 46,722 IM nail operations. 562 operations were for hip fractures or did not have a registered surgical approach and were excluded. As only 47 operations were done in high-income countries (USA 38, Australia 9), and only one of these cases had a registered follow-up, these cases were also excluded. This left 46,113 IM nail operations of the humerus, femur, or tibia to be included for analysis. An overview of the included cases and risk factors is presented in Table 1.
Infection was registered in the SOSD at the time of follow-up. Possible risk factors for infection after orthopedic trauma surgery, including age, gender, surgical approach, use of antibiotics, and operating techniques were included as variables in the analyses. Open fractures in the SOSD were classified according to Gustilo and Anderson [22]. Surgeons classified infections as superficial or deep in the SOSD; however, this distinction did not follow a strict classification. We therefore grouped all registered infections together on the assumption that registered infections are likely to be clinically significant. The duration of the operative procedure was not registered in the SOSD, but surgeons did subjectively classify a fracture as a non-union or not at the time of surgery. Non-union may be a risk factor in itself, or it might be an indirect measure of increased operating time, and it was therefore analyzed as a separate risk factor. The SIGN IM nail system uses an external target arm and "slot finder" instruments to place the distal locking screws in the nail. This technique can be challenging at times and can prolong operating time. The number of distal locking screws $(0,1$, or 2$)$ was therefore also included as another possible indirect measure of operating time.

\section{Statistics}

The $\chi^{2}$ test was used to compare rates in two different groups, and Student's $t$ test was used to compare means in two groups. Logistic regression was used to compare rates in more than two groups and to calculate both crude and adjusted risk, odds ratio (OR), of infection. All $p$ values were two-tailed, and the level of statistical significance was set to $5 \%(p<0.05)$. Analyses were performed with IBM SPSS Statistics version 19.0 (SPSS Inc., Chicago, IL).

\section{Results}

A total of 46,133 IM nail operations were included, 1,381 operations of the humerus, 27,350 of the femur, and 17,382 of the tibia. Only $18.8 \%$ of operations were in women. The mean age of the patients was 34.7 (SD 15.2) years, 40.6 (SD 18.6) years for women and 33.3 (SD 14.0) years for men $(p<0.001)$.

The total follow-up rate, defined as the percentage of IM nail operations with at least one registered follow-up visit, for all nails registered in the SOSD in November 2011 was $23.1 \%$ (95 \% CI: 22.7-23.5), this is an increase from one year before, when the follow-up rate in the SOSD was $18.1 \%$. The mean time to follow-up was 215 (SD 293) days, median 100 (range: 1-3,309) days. The over all infection rate was $1.0 \%$ (95\% CI: 0.9-1.1); 0.7\% (95\% CI: 0.6-0.8) for the humerus, $0.8 \%$ (95\% CI: 0.7-0.9) for 
Table 1 Overview of included cases in the SIGN online surgical database

\begin{tabular}{|c|c|c|c|c|}
\hline & $\begin{array}{l}\text { Number } \\
\text { of operations } \\
(\%)\end{array}$ & $\begin{array}{l}\text { Number } \\
\text { with follow-up } \\
\text { (rate in \%) }\end{array}$ & $\begin{array}{l}\text { Number } \\
\text { of open fractures } \\
\text { (rate in } \% \text { ) }\end{array}$ & $\begin{array}{l}\text { Number } \\
\text { of infections } \\
\text { (rate in \%) }\end{array}$ \\
\hline Included operations in SOSD & $46,113(100)$ & $10,684(23.1)$ & $7,831(17.0)$ & $479(1.0)$ \\
\hline \multicolumn{5}{|l|}{ Age } \\
\hline$<30$ years & $20,896(45.3)$ & $5,029(24.1)$ & $3,822(18.3)$ & $216(1.0)$ \\
\hline$\geq 30$ years & $25,217(54.7)$ & $5,655(22.4)$ & 4,009 (15.9) & $263(1.0)$ \\
\hline \multicolumn{5}{|l|}{ Gender } \\
\hline Female & $8,664(18.8)$ & $2,213(25.5)$ & $1,080(12.5)$ & $71(0.8)$ \\
\hline Male & $37,449(81.2)$ & $8,471(22.6)$ & $6,751(18.0)$ & $408(1.1)$ \\
\hline \multicolumn{5}{|l|}{ Approach } \\
\hline Antegrade humerus & $1,381(3.0)$ & $310(22.4)$ & $110(8.0)$ & $9(0.7)$ \\
\hline Antegrade femur & $17,450(37.8)$ & $4,355(25.0)$ & $1,431(8.2)$ & $130(0.7)$ \\
\hline Retrograde femur & $9,900(21.5)$ & $2,292(23.2)$ & $1,230(12.4)$ & $84(0.8)$ \\
\hline Tibia & $17,382(37.7)$ & $3,727(21.4)$ & $5,060(29.1)$ & $256(1.5)$ \\
\hline \multicolumn{5}{|l|}{ Prophylactic antibiotics } \\
\hline No & $6,538(14.2)$ & $8,666(21.9)$ & $7,478(18.9)$ & $78(1.2)$ \\
\hline Yes & $39,575(85.8)$ & $2,018(30.9)$ & $353(5.4)$ & $401(1.0)$ \\
\hline \multicolumn{5}{|l|}{ Fracture reduction } \\
\hline Closed & $12,216(26.5)$ & $8,314(19.4)$ & $5,814(17.1)$ & $102(0.8)$ \\
\hline Open & $33,897(73.5)$ & $2,370(24.5)$ & $2,017(16.5)$ & $377(1.1)$ \\
\hline \multicolumn{5}{|l|}{ Reaming method } \\
\hline None & $3,996(8.7)$ & $472(11.8)$ & $1,169(29.2)$ & $31(0.8)$ \\
\hline Hand & $41,593(90.2)$ & $10,033(24.1)$ & $6,592(15.8)$ & $440(1.1)$ \\
\hline Power & $524(1.1)$ & $179(34.2)$ & $70(13.3)$ & $8(1.5)$ \\
\hline \multicolumn{5}{|l|}{ Operation for non-union } \\
\hline No & $41,441(89.9)$ & $1,350(28.9)$ & $470(10.0)$ & $379(0.9)$ \\
\hline Yes & $4,672(10.1)$ & $9,334(22.5)$ & $7,361(17.8)$ & $100(2.1)$ \\
\hline \multicolumn{5}{|l|}{ Gustilo-Anderson grade } \\
\hline Closed & $38,297(83.1)$ & $8,881(23.2)$ & - & $293(0.8)$ \\
\hline Open grade 1 & $2,777(6.0)$ & $595(21.4)$ & $2,777(6.0)$ & $40(1.4)$ \\
\hline Open grade 2 & $2,936(6.4)$ & $681(23.2)$ & $2,936(6.4)$ & $69(2.4)$ \\
\hline Open grade $3 a$ & $1,562(3.4)$ & $383(24.5)$ & $1,562(3.4)$ & $48(3.1)$ \\
\hline Open grads $3 b$ & $467(1.0)$ & $125(26.8)$ & $467(1.0)$ & $24(5.1)$ \\
\hline Open grade $3 \mathrm{c}$ & $74(0.2)$ & $19(25.7)$ & $74(0.2)$ & $5(6.8)$ \\
\hline \multicolumn{5}{|l|}{ Country income level ${ }^{a}$} \\
\hline Low-income countries & $25,751(55.8)$ & $7,197(27.9)$ & $4,192(16.3)$ & $309(1.2)$ \\
\hline Lower middle- income countries & $17,083(37.0)$ & $3,168(18.5)$ & $3,231(18.9)$ & $153(0.9)$ \\
\hline Higher middle-income countries & $3,279(7.1)$ & $319(9.7)$ & $393(12.0)$ & $17(0.5)$ \\
\hline
\end{tabular}

${ }^{a}$ Country income level according to World Bank 2009

the femur, and $1.5 \%$ (95\% CI: 1.4-1.6) for the tibia. Crude and adjusted risks of infection for different risk factors are presented in Table 2 . If only nails with registered follow-up ( $n=10684$ ) were included, infection rates were $2.9 \%$ for fractures of the humerus $(95 \% \mathrm{CI}$ : 2.6-3.2), $3.2 \%$ (95\% CI: 2.9-3.5) for those of the femur, and $6.9 \%(95 \% \mathrm{CI}: 6.4,7.4)$ for those of the tibia.

The crude risk of infection for men was $33 \%$ higher than for women (OR 1.33, $95 \%$ CI 1.04-1.72; $p=0.026)$, but this apparent increased risk marginally lost statistically significance when adjusted for the other risk factors in Table 2 (OR 1.29, $95 \%$ CI 1.00-1.66; $p=0.053$ ).

There were $17.0 \%$ open fractures in this study. An open fracture of any grade gave a 3.16 times increased adjusted risk of infection (OR 3.16, $95 \%$ CI 2.62-3.80; $p<0.001$ ). The increased risk of infection rose from 1.86 times for a Gustilo type 1 fracture to 7.61 times increased risk for Gustilo type $3 \mathrm{c}$ fracture (Table 2). Fractures defined by the 
Table 2 Crude and adjusted risk of infection

\begin{tabular}{|c|c|c|c|c|c|c|}
\hline & $\begin{array}{l}\text { No. operations } \\
\text { (\%) }\end{array}$ & $\begin{array}{l}\text { No. infections } \\
\text { (rate in \%) }\end{array}$ & $\begin{array}{l}\text { Crude odds } \\
\text { ratio }(95 \% \mathrm{CI})\end{array}$ & $p$ value & $\begin{array}{l}\text { Adjusted odds } \\
\text { ratio }(95 \% \mathrm{CI})\end{array}$ & $p$ value \\
\hline All included operations in SOSD & $46,113(100)$ & $479(1.0)$ & & & & \\
\hline \multicolumn{7}{|l|}{ Age (years) } \\
\hline$<30$ & $20,896(45.3)$ & $216(1.0)$ & 1 & & 1 & \\
\hline$\geq 30$ & $25,217(54.7)$ & $263(1.0)$ & $1.01(0.84-1.21)$ & 0.92 & $1.01(0.84-1.21)$ & 0.96 \\
\hline \multicolumn{7}{|l|}{ Gender } \\
\hline Female & $8,664(18.8)$ & $71(0.8)$ & 1 & & 1 & \\
\hline Male & $37,449(81.2)$ & $408(1.1)$ & $1.33(1.04-1.72)$ & 0.026 & $1.29(1.00-1.66)$ & 0.053 \\
\hline \multicolumn{7}{|l|}{ Approach } \\
\hline Antegrade humerus & $1,381(3.0)$ & $9(0.7)$ & $0.87(0.44-1.72)$ & 0.70 & $0.88(0.45-1.75)$ & 0.72 \\
\hline Antegrade femur & $17,450(37.8)$ & $130(0.7)$ & 1 & $<0.001^{\mathrm{a}}$ & 1 & $<0.001^{\mathrm{a}}$ \\
\hline Retrograde femur & $9900(21.5)$ & $84(0.8)$ & $1.14(0.87-1.50)$ & 0.35 & $1.13(0.86-1.50)$ & 0.38 \\
\hline Tibia & $17,382(37.7)$ & $256(1.5)$ & $1.99(1.61-2.46)$ & $<0.001$ & $1.71(1.36-2.15)$ & $<0.001$ \\
\hline \multicolumn{7}{|l|}{ Prophylactic antibiotics } \\
\hline No & $6,538(14.2)$ & $78(1.2)$ & 1 & & 1 & \\
\hline Yes & $39,575(85.8)$ & $401(1.0)$ & $0.85(0.66-1.08)$ & 0.19 & $0.71(0.55-0.91)$ & 0.008 \\
\hline \multicolumn{7}{|l|}{ Fracture reduction } \\
\hline Closed & $12,216(26.5)$ & $102(0.8)$ & 1 & & 1 & \\
\hline Open & $33,897(73.5)$ & $377(1.1)$ & $1.34(1.07-1.66)$ & 0.010 & $1.23(0.97-1.55)$ & 0.083 \\
\hline \multicolumn{7}{|l|}{ Reaming method } \\
\hline None & $3,996(8.7)$ & $31(0.8)$ & 1 & $0.14^{\mathrm{a}}$ & 1 & $0.14^{\mathrm{a}}$ \\
\hline Hand & $41,593(90.2)$ & $440(1.1)$ & $1.37(0.95-1.97)$ & 0.093 & $1.41(0.96-2.06)$ & 0.076 \\
\hline Power & $524(1.1)$ & $8(1.5)$ & $1.98(0.91-4.34)$ & 0.086 & $1.92(0.86-4.25)$ & 0.11 \\
\hline \multicolumn{7}{|l|}{ Operation for non-union } \\
\hline No & $41,441(89.9)$ & $379(0.9)$ & 1 & & 1 & \\
\hline Yes & $4,672(10.1)$ & $100(2.1)$ & $2.37(1.90-2.96)$ & $<0.001$ & $2.31(1.83-2.91)$ & $<0.001$ \\
\hline \multicolumn{7}{|l|}{ Gustilo-Anderson grade } \\
\hline Closed & $38,297(83.1)$ & $293(0.8)$ & 1 & $<0.001^{\mathrm{a}}$ & 1 & $<0.001^{\mathrm{a}}$ \\
\hline Open grade 1 & $2,777(6.0)$ & $40(1.4)$ & $1.90(1.36-2.64)$ & $<0.001$ & $1.86(1.32-2.62)$ & $<0.001$ \\
\hline Open grade 2 & $2,936(6.4)$ & $69(2.4)$ & $3.12(2.40-4.07)$ & $<0.001$ & $2.98(2.25-3.94)$ & $<0.001$ \\
\hline Open grade $3 \mathrm{a}$ & $1,562(3.4)$ & $48(3.1)$ & $4.11(3.02-5.60)$ & $<0.001$ & $4.00(2.90-5.50)$ & $<0.001$ \\
\hline Open grads $3 b$ & $467(1.0)$ & $24(5.1)$ & $7.03(4.59-10.77)$ & $<0.001$ & $6.08(3.92-9.43)$ & $<0.001$ \\
\hline Open grade $3 c$ & $74(0.2)$ & $5(6.8)$ & $9.40(3.77-23.47)$ & $<0.001$ & $7.61(3.01-19.25)$ & $<0.001$ \\
\hline \multicolumn{7}{|l|}{ Country income level $^{\mathrm{b}}$} \\
\hline Low-income countries & $25751(55.8)$ & $309(1.2)$ & 1 & $<0.001^{\mathrm{a}}$ & 1 & $<0.001^{\mathrm{a}}$ \\
\hline Lower middle-income countries & $17083(37.0)$ & $153(0.9)$ & $0.74(0.61-0.90)$ & 0.003 & $0.71(0.58-0.86)$ & 0.001 \\
\hline Higher middle-income countries & $3,279(7.1)$ & $17(0.5)$ & $0.43(0.26-0.70)$ & 0.001 & $0.49(0.30-0.81)$ & 0.005 \\
\hline
\end{tabular}

Crude odds ratio only compares the risk of infection for the particular risk factor in question. The adjusted odds ratio is adjusted for all the other factors in the table

a Overall test

b Country income level according to World Bank 2009

surgeon preoperatively as a non-union had an adjusted risk of infection 2.31 times higher (OR 2.31, $95 \% \mathrm{CI}$ $1.83-2.91 ; p<0.001)$ than fractures that were not classified as a non-union. There was no apparent effect of the number of distal locking screws on the rate of infection (OR $0.95-1.25 ; p=0.80-0.30$ ), and this variable did not affect the adjusted risks of the other risk factors. It was therefore not included in Table 2. The method of reaming did not significantly affect the risk of infection (Table 2).

The use of prophylactic antibiotics at the time of surgery reduced the adjusted risk of infection by $29 \%$ (OR 0.71 , $95 \%$ CI $0.55-0.91 ; p=0.008)$. The apparent increase in the crude risk of infection after open reduction (OR 1.34, $95 \%$ CI $1.07-1.66 ; p=0.010)$ was not statistically 
significant after adjusting for other risk factors (OR 1.23, 95\% CI 0.97-1.55; $p=0.083$ ).

Age and gender did not significantly affect the risk of infection on more thorough sub-analysis. The same was the case when analyses were done after exclusion of countries with less than $5 \%$ follow-up, except that the difference in infection risk according to a country's income level was then no longer present $(p=0.68)$. Sub-analysis was also done after exclusion of all patients without follow-up. This left 10,684 surgeries for analysis. Also here results were mostly unchanged. However, once again the difference in risk of infection according to the income level of the country where the surgery was performed ( $p=0.30)$ was no longer statistically significant. In addition the effect of prophylactic antibiotics $(p=0.99)$ was no longer seen on exclusion of patients without follow-up.

\section{Discussion}

The main findings in the present study were that infection rates in the SOSD were low, and that the risk of infection is doubled for the delayed surgery of non-unions. When the results of this study were compared to results from the SOSD one year before [21] an increase in the follow-up rate from $18.1 \%$ (95\% CI: $17.7-18.5$ ) in 2010 to $23.1 \%$ (95\% CI: 22.7-23.5) in 2011 was observed. Despite this $27.6 \%$ increase in the follow-up rate, the infection rates in the SOSD have not risen notably. The findings that the changes in infection rates are small despite a fairly large increase in follow-up might support the observation many surgeons in low-income countries have made; that a large proportion of the patients who have specific complaints do return for follow-up, whereas patients with no complaints do not return, due, among other things, to the high cost of transport [23]. In the previous article mentioned above, we looked at the effect of the low follow-up rate in the SOSD on the infection rates [21]. In that article the statistical model suggested that the data in the SOSD might support this, as countries registering more than $5 \%$ follow-up had very little difference in infection rates, and no increase in infection rates was found with increasing follow-up rates over $5 \%$.

The infection rates in the present study are comparable to published infection rates in high-income countries [24-26], even in the higher end of the range [27]. However, there is a widespread belief among surgeons that the risk of postoperative infection is very high in LMIC. This probably stems from the personal experiences of many visiting surgeons through the years who have seen an abundance of osteomyelitis, late-presenting open fractures, and badly performed internal fixations done by undertrained local and visiting surgeons in LMIC. SIGN, however, trains surgeons in the correct setup, indications, and techniques, and all reported X-rays are reviewed and commented on by SIGN staff if they show results that are not satisfactory. There is no reason that infection rates should be much higher in a low resource setting when well-trained surgeons with modern equipment have access to the basic requirements for surgery, such as autoclaves, antiseptic wash, and the right prophylactic antibiotics, as they increasingly have in even the poorest countries. In a large randomized study of prophylactic antibiotic use in Uganda, the rate of infection after inguinal hernia repair dropped from 7.5 to $0 \%$ with correct antibiotic usage [28]. In our study prophylactic antibiotics reduced the risk of infection by $29 \%$ (OR 0.71, $95 \% \mathrm{CI}$ : 0.55-0.91). A prospective multi-center study comparing results of a standardized IM nailing technique between a South African trauma center and European centers showed lower complication rates in South Africa and a near-identical infection rate despite more serious injuries in the South African patients [19]. One explanation for this can be a lower mean age of the patients in South Africa. Trauma is a growing epidemic among the young people of LMIC [4, 5]. This can also be seen in the SOSD, where the mean age is only 34.7 years.

The second interesting finding in this study was that fractures defined by the surgeon as a non-union prior to surgery had a 2.3 times increased adjusted risk of infection (OR 2.31, $95 \%$ CI: 1.83-2.91). It is no news to orthopedic surgeons that operating to repair a non-union of the femur is a lot more work than operating on an acute fracture. The exposure is larger, the operating time longer, and the expected bleeding greater than with primary fracture surgery. In addition, it is possible that unknown factors regarding the biology of the fracture may be less favorable in non-unions. Though the definition of a non-union was at the discretion of the surgeons reporting the surgery, and might not reflect exactly the common definition of a fracture not healed at 6 months, it nevertheless is an expression of the surgeon's doing surgery for a fracture at a delayed point in time when healing is not expected to occur. As such, in the authors' opinion, this is an important finding, suggesting that outcomes are better when primary fracture surgery is done in LMIC, and in consequence that primary IM nailing should be offered for femur fractures in centers where the infrastructure and training of the surgeons allows. In uncomplicated closed tibia and humerus fractures, where there are good results of primary functional bracing that does not necessitate long-term hospital stay, this should probably still be the first-line treatment of choice [29-32].

Infection risk decreased with increasing country income level in this study, with higher middle-income countries having half the adjusted risk of infection that was seen in low-income countries (OR 0.49, $95 \%$ CI: 0.30-0.81). 
Although this is a common preconception among surgeons, to our knowledge this has not been shown in an isolated study before. This would support the notion that the lack of infrastructure and the high prevalence of malnutrition and immunosuppression in low-income countries leads to an increased risk of infection in orthopedic trauma surgery. However, the numbers registered in higher middle-income countries are low, and these figures should be interpreted with caution. Even if these risk estimates are accurate, the risk of infection in low-income countries is still low and should not prohibit the use of modern orthopedic trauma surgery in these countries.

Tibia fractures had a twofold increased crude risk of infection and a $71 \%$ increased adjusted risk of infection when an IM nail was used compared to antegrade nailing of the femur. As the adjusted risk of postoperative infection was adjusted for the increased incidence of open fractures of the tibia compared to the femur, this increase in infection risk is probably attributable to the subcutaneous localization of the tibia in contrast to the femur, which is surrounded by large, well-perfused muscles. No significant difference in the risk of infection was found between retrograde and antegrade nailing of the femur or between humerus and femur fractures.

There were $17 \%$ open fractures in this study. This relatively high proportion of open fractures can possibly be seen as an expression of the severity of trauma in patients selected for IM nailing in LMIC. Open fractures had a 3.2 times increased risk of infection overall compared to closed fractures. The adjusted risk of infection rose with increasing severity of the injury from an OR of 1.9 for Gustilo grade 1 injuries to 7.6 for grade 3C injuries (Table 2). This is in line with other published reports and further supports that the data in the SOSD can be trusted $[22,33,34]$. No effect was seen on the adjusted risk of infection from age, gender, open reduction, number of distal locking screws, or method of reaming in this study.

There are some obvious limitations to this study, the most important being the low follow-up rate in the SOSD. Limited follow-up in studies in resource-constrained settings is a well-known problem. However, this might be necessary to accept if a large body of important information from poor countries is not to be kept out of the literature. In our above-mentioned earlier article validating the data in the SOSD in late 2010, we reported a follow-up rate of $18.1 \%$ [21]. In that article we argued the case that the whole database can be used to estimate risk of infection based on the assumption that patients who have not returned for follow-up do not have infection. The present study builds on that assumption. We have also had to make several other assumptions that may not be correct. We have grouped superficial and deep infections together on the assumption that if they are reported they are serious enough to be of clinical importance, and we have assumed that if a patient returns with a complaint it will be registered in the SOSD. All this introduces uncertainty into the analyses and conclusions. However, in light of our former study, the large numbers in the SOSD, and the fact that we have analyzed the data both including and excluding patients without follow-up, we believe the reported figures give a good indication of where the true figures lie.

\section{Conclusions}

This study seems to confirm the expected increase in postoperative infection risk in low-income countries compared to countries with higher income levels, and presumably better infrastructure, but the increase in infection rates was small $(0.5-1.2 \%)$. The overall infection rates were low, and well within acceptable levels, suggesting that it is safe to do IM nailing in low-income countries. The fact that operations for non-union have twice the risk of infection compared to primary fracture surgery further supports the use of IM nailing as the primary treatment for femur fractures in LMIC.

Acknowledgments The authors are grateful to all the surgeons who in their busy settings take the time to register operations and followup in the SOSD, and who make it possible to do research into the safety of modern orthopedic trauma surgery in low and middle income countries.

Financial disclosure S.Y. has received a PhD grant (No. 911638) from the Western Norwegian Regional Health Authority (HelseVest). No other authors received funding for this study. No specific funding was received for this study.

Conflict of interest L.G.Z. is president and founder of SIGN Fracture Care International, a registered not-for-profit organization based in Richland, Washington, that supplies hospitals in LMIC with orthopedic surgical equipment and implants free of charge for use in the treatment of poor people.

Open Access This article is distributed under the terms of the Creative Commons Attribution License which permits any use, distribution, and reproduction in any medium, provided the original author(s) and the source are credited.

\section{References}

1. Mathers C, Fat DM, Boerma JT (2008) The global burden of disease: 2004 update. World Health Organization, Geneva

2. WHO (2006) The World Health Report 2006: working together for health. World Health Organization, Geneva

3. Kobusingye O, Guwatudde D, Lett R (2001) Injury patterns in rural and urban Uganda. Inj Prev 7:46-50

4. Peden M (2004) World report on road traffic injury prevention. World Health Organization, Geneva

5. Patton GC, Coffey C, Sawyer SM et al (2009) Global patterns of mortality in young people: a systematic analysis of population health data. Lancet 374:881-892 
6. WHO (2009) Global status report on road safety: time for action. World Health Organization, Geneva

7. UN general assembly resolution 55/2. Accessed 1 Sep 2011

8. Ozgediz D, Riviello R (2008) The "other" neglected diseases in global public health: surgical conditions in sub-Saharan Africa. PLoS Med 5:e121

9. PLoS Medicine Editors (2008) A crucial role for surgery in reaching the UN millennium development goals. PLoS Med 5:1165-1167

10. Farmer PE, Kim JY (2008) Surgery and global health: a view from beyond the OR. World J Surg 32:533-536. doi:10.1007/ s00268-008-9525-9

11. Bickler SW, Spiegel D (2010) Improving surgical care in lowand middle-income countries: a pivotal role for the World Health Organization. World J Surg 34:386-390. doi:10.1007/s00268009-0273-2

12. Bae JY, Groen RS, Kushner AL (2011) Surgery as a public health intervention: common misconceptions versus the truth. Bull WHO 89:394

13. Mock CN, Gloyd S, Adjei S et al (2003) Economic consequences of injury and resulting family coping strategies in Ghana. Accid Anal Prev 35:81-90

14. Kevau I, Watters DA (1996) Conservative management of femoral shaft fractures. P N G Med J 39:143-151

15. Gosselin R, Lavaly D (2007) Perkins traction for adult femoral shaft fractures: a report on 53 patients in Sierra Leone. Int Orthop 31:697-702

16. Feibel RJ, Zirkle LGJ (2009) Use of interlocking intramedullary tibial nails in developing countries. Techn Orthop 24:233-246. doi:10.1097/BTO.0b013e3181c2d0f9

17. Zirkle LG (2008) Injuries in developing countries-How can we help? The role of orthopaedic surgeons. Clin Orthop Relat Res 466:2443-2450

18. Bach O, Hope MJ, Chaheka CV et al (2004) Disability can be avoided after open fractures in Africa-results from Malawi. Injury 35:846-851

19. Gross T, Huettl T, Audigé L et al (2010) How comparable is so-called standard fracture fixation with an identical implant? A prospective experience with the antegrade femoral nail in South Africa and Europe. Injury 41:388-395

20. Gosselin RA, Heitto M, Zirkle L (2009) Cost-effectiveness of replacing skeletal traction by interlocked intramedullary nailing for femoral shaft fractures in a provincial trauma hospital in Cambodia. Int Orthop 33:1445-1448
21. Young S, Lie SA, Hallan G et al (2011) Low infection rates after 34,361 intramedullary nail operations in 55 low- and middleincome countries. Acta Orthop 82:737-743

22. Gustilo RB, Anderson JT (1976) Prevention of infection in the treatment of one thousand and twenty-five open fractures of long bones: retrospective and prospective analyses. J Bone Joint Surg Am 58:453-458

23. Shearer D, Cunningham B, Zirkle LG Jr (2009) Population characteristics and clinical outcomes from the SIGN online surgical database. Techn Orthop 24:273

24. Jenny JY, Jenny G, Kempf I (1994) Infection after reamed intramedullary nailing of lower limb fractures. A review of 1,464 cases over 15 years. Acta Orthop Scand 65:94-96

25. Court-Brown CM, Keating JF, McQueen MM (1992) Infection after intramedullary nailing of the tibia. Incidence and protocol for management. J Bone Joint Surg Br 74:770-774

26. Wolinsky PR, McCarty E, Shyr Y et al (1999) Reamed intramedullary nailing of the femur: 551 cases. J Trauma 46:392-399

27. Malik MH, Harwood P, Diggle P et al (2004) Factors affecting rates of infection and nonunion in intramedullary nailing. J Bone Joint Surg Br 86:556-560

28. Reggiori A, Ravera M, Cocozza E et al (1996) Randomized study of antibiotic prophylaxis for general and gynaecological surgery from a single centre in rural Africa. Br J Surg 83:356-359

29. Sarmiento A, Latta LL (1999) Functional fracture bracing. J Am Acad Orthop Surg 7:66-75

30. Wallny T, Sagebiel C, Westerman K et al (1997) Comparative results of bracing and interlocking nailing in the treatment of humeral shaft fractures. Int Orthop 21:374-379

31. Papasoulis E, Drosos GI, Ververidis AN et al (2010) Functional bracing of humeral shaft fractures. A review of clinical studies. Injury 41:e21-e27

32. Koch PP, Gross DFL, Gerber C (2002) The results of functional (Sarmiento) bracing of humeral shaft fractures. J Shoulder Elbow Surg 11:143-150

33. Ameya SK (2011) Infection rates in open fractures of the tibia: is the 6-hour rule fact or fiction? Adv Orthop. doi:10.4061/2011/ 943495

34. Harley BJ, Beaupre LA, Jones CA et al (2002) The effect of time to definitive treatment on the rate of nonunion and infection in open fractures. J Orthop Trauma 16:484-490 